\title{
COVALENT CROSS-LINKING OF PORCINE SMALL-INTESTINE MICROVILLAR AMINOPEPTIDASE. SUBUNIT STRUCTURE OF THE MEMBRANE-BOUND AND THE SOLUBILIZED ENZYME*
}

\author{
by \\ BIRTE SVENSSON
}

\author{
Department of Biochemistry $\mathrm{C}$, The Panum Institute, \\ University of Copenhagen, Blegdamsvej 3, DK-2200 Copenhagen N \\ and \\ Present address: Department of Chemistry, Carlsberg Laboratory, \\ Gamle Carlsberg Vej 10, DK-2500 Copenhagen Valby
}

Keywords: Microvillar aminopeptidase, subunit structure, porcine small-intestine, covalent cross-linking, peptide mapping

\footnotetext{
* Part of this work was presented at the FEBS/SKMB Advanced Course on Membrane Proteins, 10-16th September 1979, Gwatt, Switzerland
}

The porcine intestinal microvillar aminopeptidase (EC 3. 4. 11.2) consists of three types of subunits, $\alpha, \beta$ and $\gamma$, of molecular weights determined to $168.000,118,000$ and 54.000 , respectively. The isolated detergent-form of the enzyme was cross-linked in dilute solution in the presence of Triton X-100 by diimidates varying in chain length from five to twelve carbon atoms. The tendency of the subunits to participate in inter-protomer crosslinking depended on the chain length of the reagent as shown by polyacrylamide gel electrophoresis in the presence of dodecyl sulfate. Diimidates of chain lengths from seven to twelve carbon atoms caused formation of products of molecular weights up to about 660.000 , whereas the six carbon atom diimidate generated complexes lower in molecular weight and the five carbon atom diimidate introduced very few inter-protomer crosslinkages.

Cross-linking of brush border membrane vesicles, with dimethylsuberimidate, followed by Triton X-100 solubilization and isolation of the microvillar aminopeptidase by immunoadsorbent chromatography on antiaminopeptidase M-Sepharose, indicated a maximum molecular weight of the membrane-bound enzyme of 330.000 . The $\beta$ - and $\gamma$-polypeptide chains were previously demonstrated to be formed by limited proteolysis of the $\alpha$-polypeptide chain. Peptide mapping excluded the possibility of the $\gamma$-chain being generated from the $\beta$ chain. The subunit structures of the membrane-bound enzyme were suggested as $\alpha_{2}, \alpha \beta \gamma$, and $\beta_{2} \gamma_{2}$.

Small amounts of a larger polypeptide chain of molecular weight 330.000 are present in preparations of microvillar aminopeptidase. Peptide mapping indicated structural homology between this component, termed $2 \alpha$, and $\alpha, \beta$ and $\gamma$. It is suggested that the large polypeptide is a precursor of the intestinal aminopeptidase. 


\section{INTRODUCTION}

The microvillar aminopeptidase (EC 3. 4. 11.2 ) has been isolated in a detergent-form from pig small-intestine $(21,28)$ and kidney $(32)$. The intestinal enzyme is an amphiphilic protein containing three types of polypeptide chains of which the apparent molecular weights were reported by MAROuX et al. to $130.000,96.000$ and $48.000(21)$ and by SıӧsTRöm et al. to $162.000,123.000$ and $61.000(28)$, respectively. The kidney enzyme contains only the large polypeptide chain (32). These polypeptides have been classified as subunits $(21,32)$ and they will in the following be referred to as $\alpha, \beta$ and $\gamma$. The molecular weight of the detergent-form of intestinal aminopeptidase has not been determined, while a value of around one million was estimated for the homologous kidney enzyme (32). Trypsin releases hydrophobic fragments of around 10.000 dalton from the detergent-form of the intestinal and the renal enzyme with concomitant formation of a hydrophilic protein of molecular weight $280.000(20,21,32)$. The isolated detergent-form can probably be described as an aggregate of enzyme molecules established via the short hydrophobic segments (28, 32). Recently an intestinal microvillar aminopeptidase containing only the large polypeptide chain, $\alpha$, was isolated from a pig with a ligation of the pancreatic duct (28). Trypsin in vitro converts this enzyme and the renal enzyme into a form containing both $\alpha$ and the two smaller polypeptides, $\beta$ and $\gamma(28,32)$. The pancreatic protease was therefore suggested to be responsible for a similar cleavage of the intestinal enzyme to occur in vivo $(28,32)$. At present molecular size and subunit stoichiometry have not been described for the membrane-bound form or for the isolated detergent-form of intestinal microvillar aminopeptidase.

The method of covalent cross-linking has been applied to interpret the stoichiometry and quarternary structure of isolated oligomeric proteins $(5,7)$, and its use has been extended to investigate the topography of membrane proteins $(12,24)$. Although many types of membranes have been studied, most experiments were carried out on the erythrocyte. Several specific associations between polypeptides of this membrane were suggested from two-dimensional electrophoretic analyses of membrane polypeptides cross-linked by cleavable reagents $(14,33)$. However, detailed analysis of the subunit structure of individual membrane-bound oligomeric proteins exists only in the case of proteins localized to membranes containing one or a few major polypeptides such as for example the $\mathrm{Ca}^{2+}$-stimulated ATP-ase of sarcoplasmic reticulum (1), the acetyl choline receptor in membranes from nervous tissue (10), and the spike of Semliki Forest virus (34).

The intestinal brush border membrane shows a complex polypeptide composition in SDSpolyacrylamide gel electrophoresis (18). The microvillar aminopeptidase amounts to approximately $8 \%$ of the protein contents (17) and its three types of polypeptide chains, $\alpha, \beta$ and $\gamma$, are not conspicuously identified in the electrophoretic pattern. Covalent cross-linking of brush border membranes and subsequent direct identification and characterization of polypeptide complexes derived from microvillar aminopeptidase using a two-dimensional electrophoretic technique is obviously a very difficult task. Instead, another approach was used involving treatment of brush border membrane vesicles with a bifunctional reagent followed by biospecific isolation of the enzyme and analysis of its polypeptide pattern. As the possible subunit structures to be proposed for aminopeptidase molecules will depend on whether the $\beta$ polypeptide chain can generate the $\gamma$-polypeptide chain, this point was further investigated by peptide mapping.

Initial experiments on isolated aminopeptidase in detergent-solution had indicated the reagent and experimental conditions suitable for crosslinking of the membrane-bound enzyme. Evidence compatible with $\alpha_{2}, \alpha \beta \gamma$ and $\beta_{2} \gamma_{2}$ as subunit structures of the membrane-bound enzyme was acquired by cross-linking and peptide mapping studies. Finally these quarternary structures are suggested to arise from limited proteolysis of a brush border membranebound large precursor of aminopeptidase.

Abbreviations: $C_{5}, C_{6}, C_{7}, C_{8}, C_{10}$, and $C_{12}$ correspond to pentane-, hexane-, heptane-, octane-, decane-, and dodecanediimidic acid dimethylester, respectively. SDS = sodium dodecyl sulfate. 


\section{MATERIALS AND METHODS}

\subsection{Materials}

Pig small-intestines were kindly delivered by the Department of Experimental Pathology, Rigshospitalet (Copenhagen, Denmark). Papain ( $2 \times$ crystallized, Type III), human transferrin, ovalbumin (Grade V), dimethyladipimidate dihydrochloride, and dimethylsuberimidate dihydrochloride were purchased from Sigma Chem. Comp. (St. Louis, Miss.). $\beta$-Galactosidase (E. coli) and rabbit muscle phosphorylase a were from Boehringer (Mannheim, F. R. G.), bovine serum albumin from Armour Pharmaceutical Company (Eastbourne, U. K.), $\alpha$-chymotrypsin (crystalline) was a gift from Novo Industries (Bagsværd, Denmark), and Armilłaria mellea protease was a gift from Dr. V. B. Pedersen. Department of Biochemical Genetics, University of Copenhagen, (Denmark). The high molecular weight calibration kit of proteins was from Pharmacia (Uppsala, Sweden). Diimidates of chain lengths of $5,7,10$, and 12 carbons atoms were gifts of Dr. B. L. Møller, Department of Physiology, The Carlsberg Laboratory. Dimethylsuberimidate labelled by ${ }^{14} \mathrm{C}$ at the carbonyl groups was a gift from Dr. S. BAYNE, Fachbereich Biologie, University of Konstanz (F. R. G.). Sodium dodecyl sulfate (Sequanal grade) was from Pierce (Rockford, Ill.), Triton X-100 from Roth (Karlsruhe, F. R. G.), L-alanine-4nitroanilide and Folin-Ciocalteau's reagent were products of Merck (Darmstadt, F. R. G.). Aprotinin (Kunitz trypsin inhibitor) was from Bayer (Leverkusen, F. R. G.) and agarose (type LSB) from Litex (Glostrup, Denmark).

\subsection{Purification of microvillar aminopeptidase}

All preparative steps and cross-linking experiments were carried out in the presence of Kunitz trypsin inhibitor $\left(2.8 \mu \mathrm{g} \cdot \mathrm{ml}^{-1}\right)$.

The aminopeptidase was isolated from jejunum by immunoadsorbent chromatography on anti-aminopeptidase M-Sepharose (28). Chargeshift crossed immunoelectrophoresis $(2,28)$ confirmed the enzyme to be amphiphilic and free of hydrophilic form(s). Aminopeptidase was dissociated in $0.1 \%$ SDS at room temperature, and the subunits, $\alpha, \beta$ and $\gamma$, were isolated by gel filtration in $0.01 \mathrm{~m}$-sodium fosfate $\mathrm{pH} 6.4,0.1 \%$ in SDS and $0.02 \%$ in sodium azide (SvENSSON, SJösTröm and NoRÉN, manuscript in preparation).

\subsection{Preparation of brush border membrane vesicles}

The intestine was washed and brush border membrane vesicles prepared from $300 \mathrm{~g}$ of jejunal pieces as described before $(13,28)$. The vesicles were finally suspended in $0.25 \mathrm{M}$ triethanolamine- $\mathrm{HCl}, \mathrm{pH} \quad 8.5(60 \mathrm{ml}$ final volume, $2-5 \mathrm{mg}$ protein $\cdot \mathrm{ml}^{-1}$ ) and either used directly for cross-linking or kept at $-80^{\circ} \mathrm{C}$ after sedimentation at $250.000 \times \mathrm{g}$ for 1 hour.

\subsection{Cross-linking of aminopeptidase in detergent-solution}

Aminopeptidase $\left(0.15 \mathrm{mg} \cdot \mathrm{ml}^{-1}\right)$ in $0.10 \mathrm{M}$ triethanolamine- $\mathrm{HCl}, \mathrm{pH} 8.5,0.1 \%$ in Triton $\mathrm{X}-100$ and $0.45 \mathrm{M}$ in $\mathrm{NaCl}$, was cross-linked at room temperature or $4^{\circ} \mathrm{C}$ by addition of the diimidates $\mathrm{C}_{5}, \mathrm{C}_{6}, \mathrm{C}_{7}, \mathrm{C}_{8}, \mathrm{C}_{10}$ to a resulting concentration of $0.02 \mathrm{M}$ or $\mathrm{C}_{12}$ of $0.003 \mathrm{M}$. After $30 \mathrm{~min}$ the reaction was quenched by $0.05 \mathrm{M}$ ammonium acetate and $20 \mathrm{~min}$ later the mixtures were dialyzed exhaustively at $4{ }^{\circ} \mathrm{C}$ against $0.01 \mathrm{~m}$-Tris- $\mathrm{HCl}, \mathrm{pH} 6.8,0.1 \%$ in SDS, and lyophilized. At one occasion the crosslinking reagent was $1 \mathrm{~mm}{ }^{14} \mathrm{C}-\mathrm{C}_{8}$.

\subsection{Cross-linking of brush border membrane vesicles}

$\mathrm{C}_{8}$, freshly dissolved in $1 \mathrm{M}$-triethanolamine$\mathrm{HCl}, \mathrm{pH} 9.0$, was added to brush border membrane vesicles suspended in $0.25 \mathrm{M}$-triethanolamine- $\mathrm{HCl}, \mathrm{pH} 8.5\left(2-5 \mathrm{mg}\right.$ protein $\left.\cdot \mathrm{ml}^{-1}\right)$ as three equal portions with $15 \mathrm{~min}$ intervals to a resulting concentration of $0.015 \mathrm{~m}$. The reaction took place at room temperature or $4{ }^{\circ} \mathrm{C}$ during gentle stirring and it was quenched $40 \mathrm{~min}$ after the first addition of $\mathrm{C}_{8}$ by $0.03 \mathrm{M}$-ammonium acetate. After another $20 \mathrm{~min}$ the membrane vesicles were isolated by centrifugation at $250.000 \times \mathrm{g}$ for 1 hour, resuspended in $60 \mathrm{ml}$ of $0.05 \mathrm{~m}$-Tris- $\mathrm{HCl}, \mathrm{pH} \mathrm{8.0,1} \%$ Triton X-100, and left slowly stirring for 1 hour at $4{ }^{\circ} \mathrm{C}$. Solubilized material remaining in the supernatant after centrifugation at $250.000 \times \mathrm{g}$ for 1 
hour was subjected to immunoadsorbent chromatography on anti-aminopeptidase M-Sepharose as described (28). The aminopeptidase containing fractions were pooled and concentrated by ultrafiltration (8) to approximately $1 \mathrm{mg}$ protein $\cdot \mathrm{ml}^{-1}$ and kept at $-20^{\circ} \mathrm{C}$.

\subsection{SDS-Polyacrylamide slab-gel electrophoresis}

The electrophoresis were carried out in $0.1 \%$ SDS using the discontinuous buffer system of Laemmli having $0.75 \mathrm{M}$-Tris in the separation gel and $0.05 \mathrm{~m}$-Tris and $0.38 \mathrm{~m}$-glycine in the electrode buffer $(15,31)$. The composition of acrylamide: bisacrylamide was $30: 0.2$ and $30: 0.8$ by weight for the separation and stacking gel solutions, respectively. The height of the $3 \%$ stacking gel was $20 \mathrm{~mm}$. The slot width was always $10 \mathrm{~mm}$. The thickness was 1.0 and 1.3 $\mathrm{mm}$ for first and second dimensional gels, respectively.

Separation of cross-linked products of aminopeptidase was performed in gels made by a 3.5 to 12 or $15 \%$ linear gradient of acrylamide stabilized by a $4-17 \%$ linear gradient of sucrose (200 $\mathrm{mm}$ separation gel). For peptide mapping a $15 \%$ polyacrylamide separation gel was used $(200 \mathrm{~mm})$. The samples were reduced and denatured as described by LAEMMLI (15) and the protein standard kit was pretreated as recommended by the manufacturers. Bromphenol blue was used as tracking dye. Staining and destaining were performed during slow, horizontal movement in $0.2 \%$ Coomassie Brilliant Blue $\mathrm{R}$ 250 in $50 \%$ methanol and $7 \%$ acetic for a minimum of 2 hours. Rapid destaining was obtained using the same solvent. For fluorography of separated ${ }^{14} \mathrm{C}-\mathrm{C}_{8}$-aminopeptidase the gel was soaked in a solution of 2,5-diphenyloxazole (PPO) in dimethylsulfoxide as described by BONNER and LASKEY, dried and placed on a Kodak XL-1 film at $-80^{\circ} \mathrm{C}(3,19)$.

\subsection{Peptide mapping}

The procedure described by Cleveland et al. involving partial enzymic proteolysis in the presence of SDS and analysis of the cleavage products by polyacrylamide gel electrophoresis (6) was modified for use in a two-dimensional system. The polypeptide chains of aminopeptidase were separated in a $10 \%$ polyacrylamide slab $(100 \mathrm{~mm})$. The lanes were cut out and soaked for $30 \mathrm{~min}$ at room temperature with stacking gel buffer containing protease. The second dimensional gel $(1.3 \times 320 \times 200 \mathrm{~mm})$ was freshly overlayered to a height of $2 \mathrm{~mm}$ with $1 \%$ agarose (melting point $35^{\circ} \mathrm{C}$ ) in stacking gel buffer containing $10 \%$ 2-mercaptoethanol. The first dimensional gel lanes ( 2 or 3 ) were transferred to the top of the second dimensional gel and sealed in with agarose.

The Armillaria mellea protease could not be directly employed in the stacking gel buffer and peptide mapping was instead performed on the isolated subunits. An aliquot of subunit containing eluate $(36 \mu \mathrm{l})$ was added to $0.2 \mathrm{M}$-Tris- $\mathrm{HCl}$, $\mathrm{pH} 8.0,4 \%$ in SDS, $(4 \mu \mathrm{l})$ and heated to $100^{\circ} \mathrm{C}$ for $5 \mathrm{~min}$. Then the protease $(8 \mu \mathrm{l})$ was added and the incubation took place at $37^{\circ} \mathrm{C}$. The reaction was stopped by addition of $1.75 \mathrm{M}$-Tris$\mathrm{HCl}, \mathrm{pH} 6.8,50 \%$ in glycerol, $10 \%$ in 2 mercaptoethanol, $10 \%$ in SDS, $0.005 \%$ in bromphenol blue $(12 \mu \mathrm{l})$ and heating at $100^{\circ} \mathrm{C}$ for $2 \mathrm{~min}$. This mixture was directly applied to the SDS-polyacrylamide slab.

\subsection{Analyses}

Amino acid composition was determined from samples hydrolyzed by $6 \mathrm{~N} \mathrm{HCl}$ in evacuated ampouls for 24,48 or 72 hours at $110^{\circ} \mathrm{C}$ and analyzed on a Durrum D-500 analyzer. The extent of modification of $\varepsilon$-amino groups was determined by carbamylation ( 29 , 30). Contents of homocitrulline were extrapolated to zero time of hydrolysis and the difference obtained between unmodified and $\mathrm{C}_{8}$-crosslinked aminopeptidase was used to calculate the degree of reaction with diimidate.

Aminopeptidase activity and protein contents were measured as earlier described (28).

\section{RESULTS}

\subsection{Cross-linking of isolated aminopeptidase}

The amphiphilic aminopeptidase elutes as a single symmetrical peak in gel filtration chromatography at high concentration of salt in presence of nonionic detergent (28). Similar experimental conditions were used in the present cross-linking 


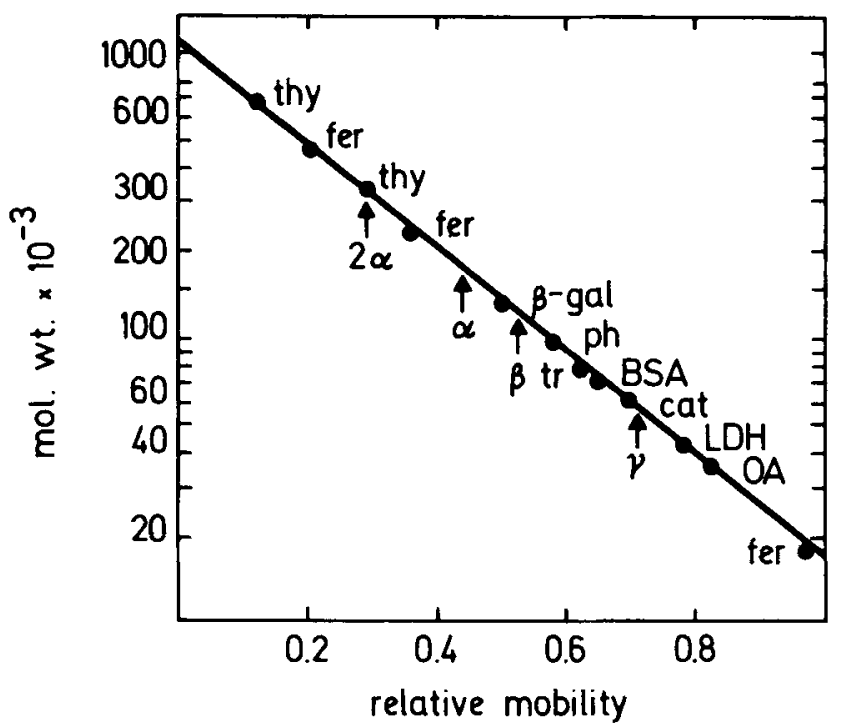

Figure 1. Calibration curve for molecular weights of polypeptides analyzed on a 3.5-15\% SDS-polyacrylamide gel.

The exclusion limit is around $10^{6}$ dalton. The markers are: Thyroglobulin $(660.000,330.000)$, ferritin $(440.000,220.000,18.500), \beta$-galactosidase $(130.000)$, phosphorylase a $(94.000)$, transferrin $(76.000)$, serum albumin (68.000), catalase (60.000), ovalbumin (43.000), and lactate dehydrogenase (36.000). The relative mobilities of the polypeptide components of aminopeptidase, $2 \alpha, \alpha, \beta$ and $\gamma$, are indicated.

studies to avoid excessive aggregations of the integral membrane protein. Treatment with a series of diimidates varying in chain length resulted in formation of soluble, cross-linked forms of aminopeptidase. The same calibration curve was used for estimation of molecular weights of cross-linked products and free subunit polypeptide chains, $\alpha, \beta$ and $\gamma$ of apparent molecular weights $168.000,118.000$ and 54.000 , respectively (Figure 1). A maximum size for aminopeptidase polypeptide complexes around 660.000 was attained using $\mathrm{C}_{7}, \mathrm{C}_{8}, \mathrm{C}_{10}$ or $\mathrm{C}_{12}$ (Figure 2). $\mathrm{C}_{6}$ did not form similarly large products, while $\mathrm{C}_{5}$ caused very little interprotomer cross-linking. The longer chain length diimidates, $\mathrm{C}_{10}$ and $\mathrm{C}_{12}$, formed a larger number of different and not always as well resolved products as $\mathrm{C}_{6}, \mathrm{C}_{7}$ and $\mathrm{C}_{8}$. Furthermore, the contents in band 16 (free $\gamma$ ) and band 15 (dimeric $\gamma$ ) were smaller, whereas the contents in band 12 (presumably $\alpha \gamma$ and $\gamma_{4}$ ) were higher in $\mathrm{C}_{10^{-}}$and

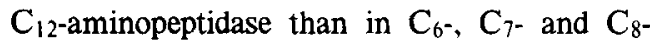
aminopeptidase. The relative amounts in band 14 (free $\beta$ ) were higher in $\mathrm{C}_{6^{-}}, \mathrm{C}_{10^{-}}$and $\mathrm{C}_{12^{-}}$ aminopeptidase, while the contents in band 13 (free $\alpha$ ) were low in all $\mathrm{C}_{6}-\mathrm{C}_{12}$ cross-linked preparations of the enzyme. Cross-linking by $\mathrm{C}_{6}$ or $\mathrm{C}_{8}$ at $4{ }^{\circ} \mathrm{C}$ resulted in polypeptide patterns essentially identical to the ones shown in Figure 2. A tentative assignment of subunit composition to the bands in Figure 2 will be discussed in section 4 .

\subsection{Cross-linking and isolation of membrane- bound aminopeptidase}

$\mathrm{C}_{8}$ was chosen for cross-linking of aminopeptidase in situ because reaction of isolated enzyme with $\mathrm{C}_{8}$ had resulted in distinctly migrating products covering the whole size range from 54.000 to 660.000 dalton (Figure 2).

Solubilization of $\mathrm{C}_{8}$-cross-linked brush border membrane vesicles (see section 2.3) yielded about $50 \%$ of the protein and about $70 \%$ of the enzymic activity as compared to non-crosslinked membranes from the same preparation. The $\mathrm{C}_{8}$-aminopeptidase subsequently isolated by immunoadsorbent chromatography displayed 


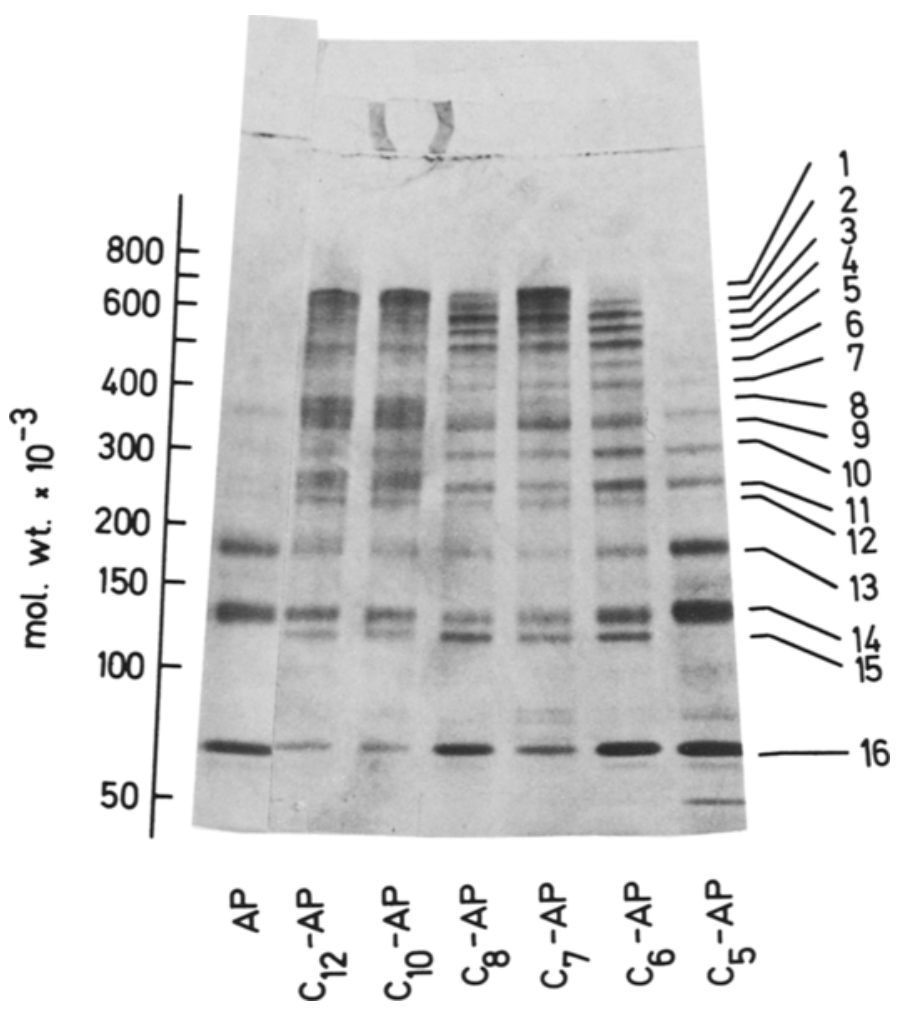

Figure 2. Polypeptide pattern of isolated aminopeptidase (AP) cross-linked in solution by $\mathrm{C}_{5}, \mathrm{C}_{6}, \mathrm{C}_{7}, \mathrm{C}_{8}, \mathrm{C}_{10}$ and $\mathrm{C}_{12}$ analyzed on a $3,5-12 \%$ SDS-polyacrylamide gel.

In all cases approximately $20 \mathrm{\mu g}$ of protein was applied. The proposed compositions of the bands are listed in Table II (section 4).

around $90 \%$ of the specific activity of the unmodified enzyme, indicating that cross-linking only affects the enzymic function to a small extent.

The polypeptides of in situ $\mathrm{C}_{8}$-cross-linked aminopeptidase all had a counterpart of identical size among the polypeptides found in aminopeptidase cross-linked by $\mathrm{C}_{8}$ in solution (compare
Figures 3 and 2). The most intensely stained band of cross-linked products had a molecular weight about 330.000 (band 9, Figure 3). Larger complexes were present in trace amounts only, suggesting the size of the aminopeptidase in the membrane-bound state to be about 330.000 dalton. At the experimental conditions interprotomer reactions within the same aminopepti-

Figure 3. Polypeptide pattern of aminopeptidase cross-linked by $\mathrm{C}_{8}$ in situ and isolated by immunoadsorbent chromatography as analyzed on a 3,5-15\% SDS-polyacrylamide gel.

Approximately $30 \mu \mathrm{g}$ of $\mathrm{AP}$ and $40 \mu \mathrm{g}$ of the in situ cross-linked enzyme, $\mathrm{C}_{8}-\mathrm{AP}$, was applied. The band numbering system is identical to that of the aminopeptidase cross-linked in solution (Figure 2) and the proposed polypeptide compositions are given in Table I.

Figure 4. Polypeptide pattern of isolated aminopeptidase cross-linked by ${ }^{14} \mathrm{C}_{-} \mathrm{C}_{8}$ compared with in situ prepared $\mathrm{C}_{8}$-aminopeptidase $\left(\mathrm{C}_{8}\right.$-AP) and unmodified aminopeptidase (AP), analyzed on a $3,5-15 \%$ SDSpolyacrylamide gel.

Approximately $20 \mu \mathrm{g}$ of ${ }^{14} \mathrm{C}-\mathrm{C}_{8}$ - $\mathrm{AP}, 40 \mu \mathrm{g}$ of $\mathrm{C}_{8}$-AP and $30 \mu \mathrm{g}$ of AP was applied. A. Coomassie Brilliant Blue staining. B. Fluorography. 
Fig. 3

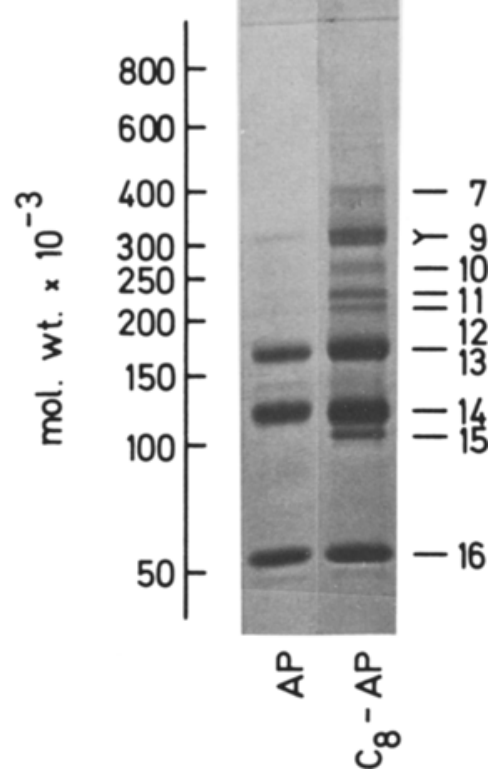

Fig. 4
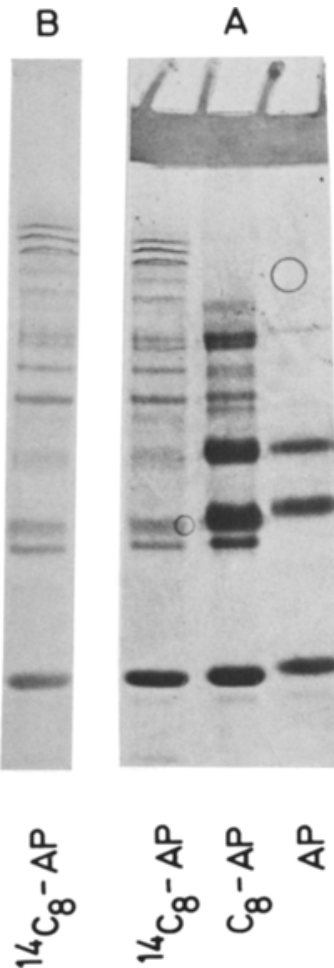

dase oligomer apparently were favoured over cross-linking between individual aminopeptidase molecules and between aminopeptidase and other proteins.

Aminopeptidase, which had not been exposed to trypsin in vivo, contained only the $\alpha$ polypeptide chain (28). This enzyme was converted by trypsin in vitro into a form consisting of $\alpha, \beta$ and $\gamma$-subunits (28) like ordinary aminopeptidase. The membrane-bound aminopeptidase from the pig with ligated pancreatic duct was found by $\mathrm{C}_{8}$-cross-linking in situ to have a molecular weight of 330.000 , and thus the subunit structure $\alpha_{2}$. In the normal pig limited proteolysis by endogenous pancreatic protease(s) of $\alpha_{2}$ is suggested. Since it is later demonstrated that the sequences of $\beta$ and $\gamma$ are contained in that of $\alpha$, but $\beta$ is unlikely to undergo further hydrolysis with formation of $\gamma$ the resulting subunit structures are likely to be $\alpha \beta \gamma$ and $\beta_{2} \gamma_{2}$.

A tentative assignment of the bands of in situ cross-linked aminopeptidase based on their molecular weights is given in Table I. In a different experiment the composition of the bands 10-16 was confirmed by introduction of cleavable cross-linkages (Svensson, Suöström and NORÉN, manuscript in preparation).

Cross-linking of brush border membrane vesicles at $4{ }^{\circ} \mathrm{C}$ resulted in a polypeptide pattern of cross-linked aminopeptidase indistinguishable from the pattern shown in Figure 3.

\subsection{Chemical properties of $\mathrm{C}_{\mathbf{8}}$-aminopeptidase}

In unmodified aminopeptidase $13 \%$ of the $\varepsilon$ amino groups were not accessible for carbamylation as compared to $33 \%$ in the aminopeptidase cross-linked by $\mathrm{C}_{8}$ in situ. Thus $20 \%$ of the lysyl groups had participated in inter- or intrapolypeptide chain cross-linking or in monofunctional substitution. Reaction of isolated aminopeptidase with $1 \mathrm{~mm}$ of ${ }^{14} \mathrm{C}-\mathrm{C}_{8}$ resulted in a degree of modification of lysyl groups of $20 \%$. By fluorography after SDS-polyacrylamide gel electrophoresis of ${ }^{14} \mathrm{C}-\mathrm{C}_{8}$-aminopeptidase, the free $\beta$ - and $\gamma$-polypeptides contained radioactivity, confirming intra-polypeptide chain crosslinking and/or monofunctional substitution to occur to a significant extent (Figure 4). 
Table I

Analysis of the band pattern of aminopeptidase cross-linked in situ by $\mathrm{C}_{8}$.

\begin{tabular}{|c|c|c|c|}
\hline Band & $\begin{array}{c}\text { Apparent } \\
\text { mol.wt. }\end{array}$ & $\begin{array}{l}\text { Proposed } \\
\text { subunit } \\
\text { composition }\end{array}$ & $\begin{array}{c}\text { Calculated } \\
\text { mol.wt. }\end{array}$ \\
\hline 7 & 395.000 & $\begin{array}{l}\alpha_{2} \gamma \\
\alpha \beta \gamma_{2} \\
\beta_{2} \gamma_{3}\end{array}$ & $\begin{array}{l}390.000 \\
394.000 \\
398.000\end{array}$ \\
\hline 9 & $335.000 / 310.000$ & $\begin{array}{l}\alpha_{2} \\
\alpha \beta \gamma \\
\beta_{2} \gamma_{2}\end{array}$ & $\begin{array}{l}336.000 \\
340.000 \\
344.000\end{array}$ \\
\hline 10 & $280.000 / 270.000$ & $\begin{array}{l}\alpha \beta \\
\beta_{2} \gamma\end{array}$ & $\begin{array}{l}286.000 \\
290.000\end{array}$ \\
\hline 11 & 230.000 & $\begin{array}{l}\beta_{2} \\
\beta \gamma_{2}\end{array}$ & $\begin{array}{l}236.000 \\
226.000\end{array}$ \\
\hline 12 & 215.000 & $a \gamma$ & 222.000 \\
\hline 13 & 168.000 & $\begin{array}{l}\alpha \\
\beta \gamma\end{array}$ & $\begin{array}{l}168.000 \\
172.000\end{array}$ \\
\hline 14 & 118.000 & $\beta$ & 118.000 \\
\hline 15 & 108.000 & $\gamma_{2}$ & 108.000 \\
\hline 16 & 54.000 & $\gamma$ & 54.000 \\
\hline
\end{tabular}

\subsection{Peptide mapping}

The structural relationship between the aminopeptidase subunits, $\alpha, \beta$ and $\gamma$, were investigated by partial proteolysis and peptide mapping. One technique employed consists in separation of the polypeptides by SDS-polyacrylamide gel electrophoresis of a preparation of aminopep- tidase, followed by incubation of the gel lanes in protease solutions. The characteristic patterns of the hereby generated peptides are then resolved in a second electrophoretic step at right angles to the first one. In two recent papers a similar system was described, where the gel lane was transferred to the new slab, and then overlayered with protease solution resulting in partial proteolysis during the stacking phase of the electrophoresis in the second dimension $(4,22)$. The present version of the technique has the advantage to allow a number of first dimensional gel lanes to be soaked in different protease solutions and analyzed in parallel in the same electrophoretic run.

In the chymotryptic digest lower molecular weight fragments of the $\alpha$ - and $\beta$-polypeptide chains were rare (Figure $5 \mathrm{~A}$ ). Major fragments of the $\alpha$-subunit of molecular weight about 60.000 and 30.000 were seen in digests of the $\beta$ and $\gamma$-subunit, respectively. Weak bands from the $\alpha$-subunit in the molecular weight range below 18.000 were of the same mobility as bands generated from the $\gamma$-subunit. Papain, in contrast, produced several smaller, distinctly migrating fragments (Figure $5 \mathrm{~B}$ ). Trace amounts of two fragments from $\beta$ of $5.000-6.000$ dalton are found in digests of $\alpha$, and $\gamma$ - and $\alpha$-digests have several bands in common in the range from 6.000-8.000 dalton and around 13.000 dalton. The information from both of these peptide maps can be summarized as the $\alpha$-subunit having parts of the primary structure identical to the $\beta$ - and the $\gamma$-subunits, whereas the $\beta$ - and the $\gamma$-subunits on the other hand appear to have no common segment in their linear sequences.

In a time course experiment using the Armillaria mellea protease, which has a narrow

Figure 5. Peptide mapping of aminopeptidase.

First dimensional separation in 10\% SDS-polyacrylamide gel and second dimensional separation in $15 \%$ SDS-polyacrylamide gel. Approximately $45 \mu \mathrm{g}$ of aminopeptidase was applied on the first dimensional gel. The gel lanes with separated $2 \alpha, \alpha, \beta$ and $\gamma$ were treated with solutions of chymotrypsin $\left(25 \mu \mathrm{g} \cdot \mathrm{ml}^{-1}\right)(\mathrm{A})$ or papain $\left(10 \mu \mathrm{g} \cdot \mathrm{ml}^{-1}\right)(\mathrm{B})$. The positions of the intact polypeptide chains after the separation in the first dimension are indicated at the bottom. The filled arrows indicate fragments common to $2 \alpha, \alpha$ and/or $\beta$. The open arrows indicate fragments common to $2 \alpha$ and/or $\alpha$ and/or $\gamma$.

Figure 6. Peptide mapping of isolated subunits $\alpha, \beta$ and $\gamma$ using Armillaria mellea protease (A.m.p.).

The incubation mixtures contained $35 \mu \mathrm{g}$ of $\alpha, 37 \mu \mathrm{g}$ of $\beta$ or $39 \mu \mathrm{g}$ of $\gamma$, the corresponding molar ratios of substrate to enzyme were 8.0,4.7 and 5.3, respectively. The subunit contents were determined by amino acid analysis assuming $23 \%$ of carbohydrate reported in aminopeptidase (21) to be equally distributed among the subunits. The time of incubation is indicated at the bottom. 
B. Svensson: Cross-linking of aminopeptidase
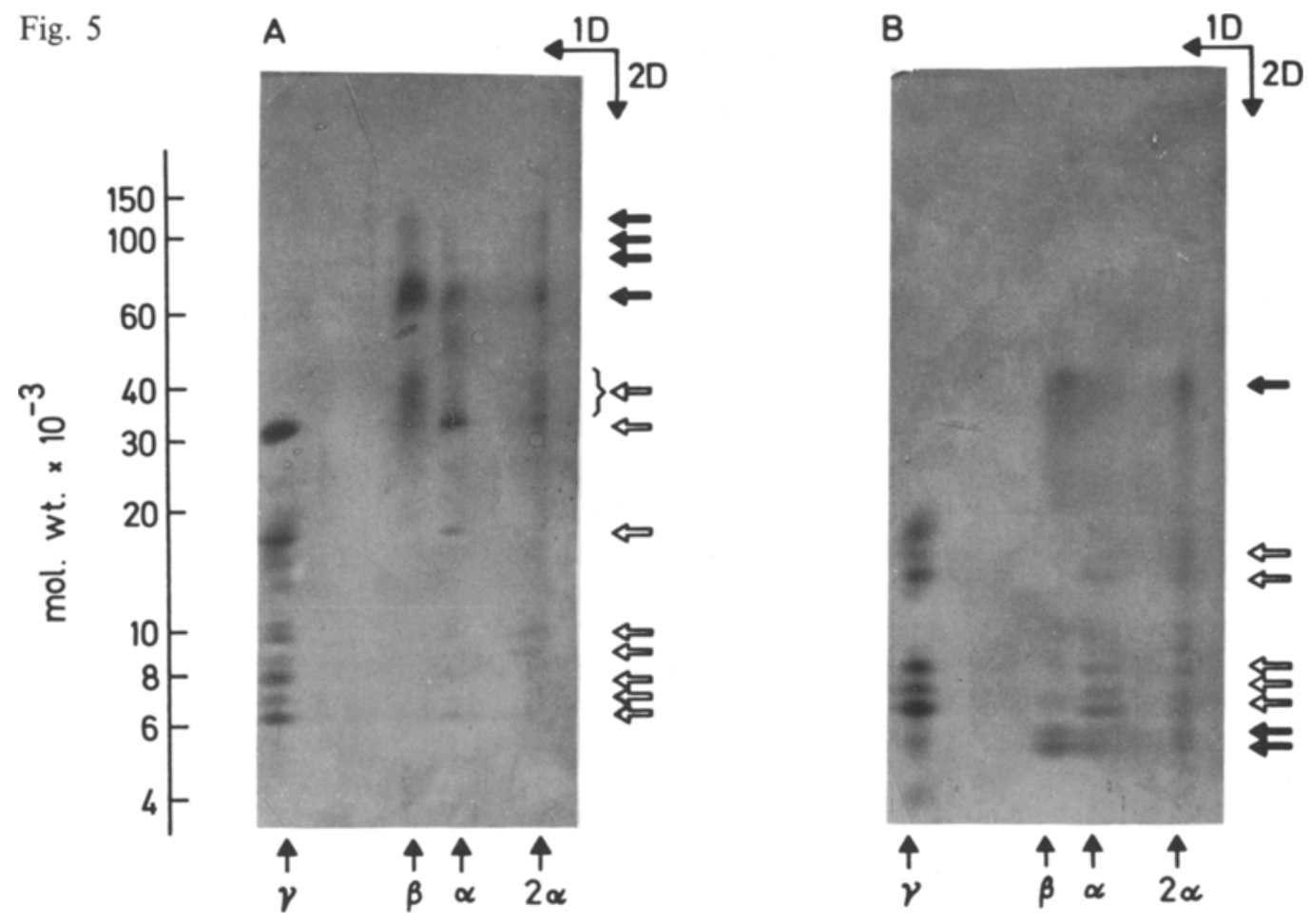

Fig. 6

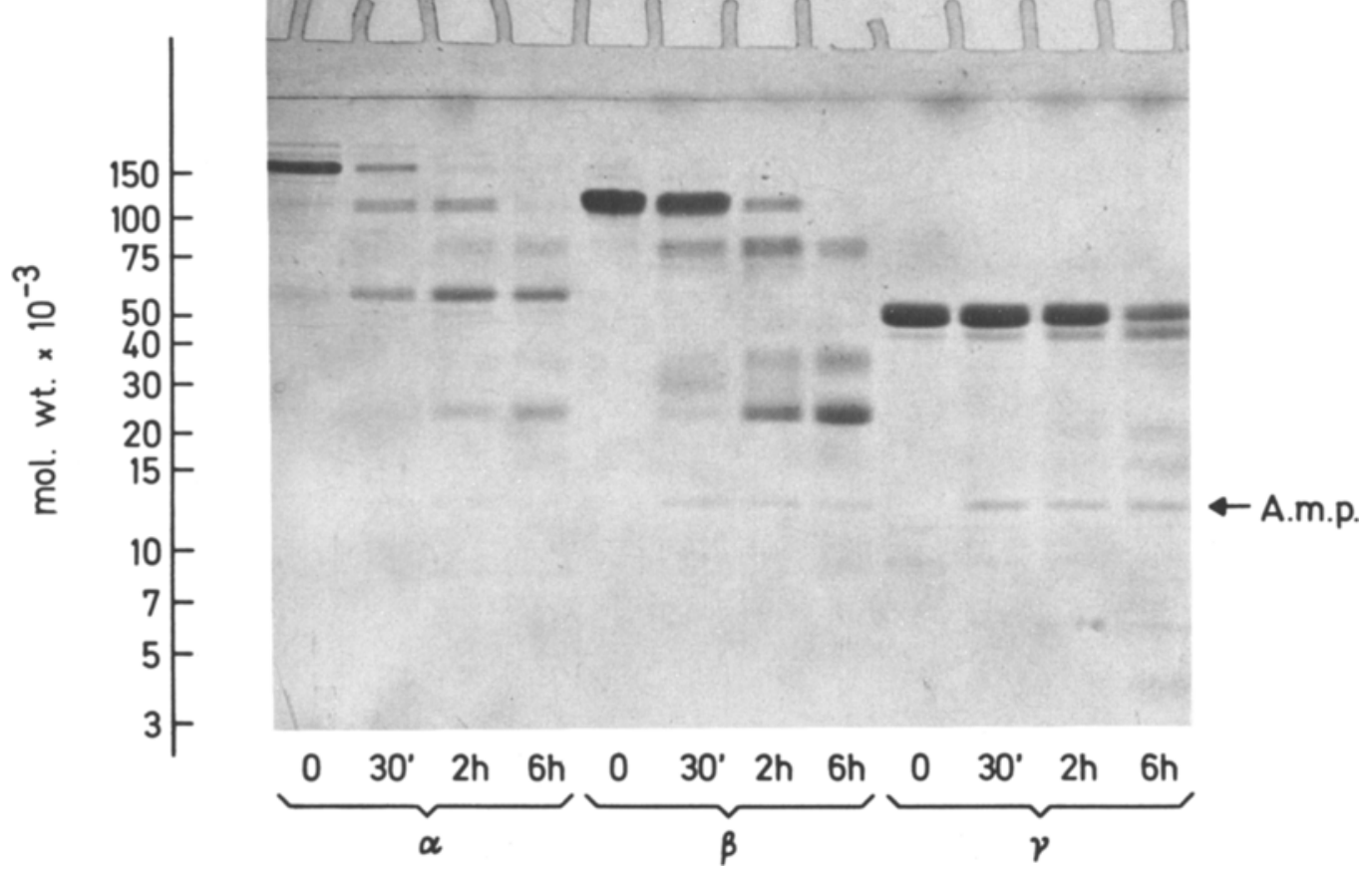


specificity towards certain peptide bonds involving the $\alpha$-amino groups of lysine residues (16), a few and mainly large fragments were expected. The $\alpha$-subunit chain gave rise to polypeptides similar in size to undegraded $\beta$ - and $\gamma$-subunits and the $\beta$-subunit seemed to be broken further down into the three major distinct fragments (Figure 6). Digestion of the $\beta$ - and the $\gamma$-subunits apparently produced no fragments of identical molecular weight (Figure 6).

The peptide maps in Figure 5 clearly indicate a fourth polypeptide of mobility lower than $\alpha$ in the first dimensional electrophoresis. It has a molecular weight in the vicinity of 330.000 , i.e. equal to $2 \alpha$, and is generally found as a minor component in preparations of intestinal aminopeptidase (see also Figures 2-4). The distinct fragments of $100.000,60.000$ and 30.000 dalton from the chymotryptic digest of $2 \alpha$ were also obtained from $\beta$, from $\alpha$ and $\beta$, and from $\alpha$ and $\gamma$, respectively (Figure $5 \mathrm{~A}$ ). In addition several weaker bands were clearly common to $2 \alpha$ and one of the subunits. In the papain digest $2 \alpha$ distinctly showed fragments around 40.000 and in the range 5.000-6.000 dalton identical to fragments of $\beta$. Bands seen in both $2 \alpha, \alpha$ and $\gamma$ digests were demonstrated in the range of 5.000-15.000 dalton (Figure 5 B). This large polypeptide thus has structural similarities with all three of the aminopeptidase subunits. It will be discussed briefly below (section 4) as a possible precursor of the form(s) of aminopeptidase which can be isolated from the intestine.

\section{DISCUSSION}

Covalent cross-linking of isolated, amphiphilic microvillar aminopeptidase at conditions where it behaves as a well-defined molecular species resulted in a range of polypeptide complexes. The concentration of protein was kept low and the ratio of protein to bifunctional reagent high in order to favour cross-linking of protomers within the same oligomer (11). Cross-linked products of apparent molecular weight greater than 660.000 were never observed, indicating the size of the aminopeptidase at the experimental conditions to be approximately twice the size reported of the hydrophilic form of the enzyme (21). One might imagine that two amphiphilic molecules in solution form a dimer via their hydrophobic anchoring segments.

The maximum molecular weight of the $\mathrm{C}_{8}$ aminopeptidase prepared in situ turned out to be 330.000 , i.e. slightly higher than that of the hydrophilic form obtained by limited proteolysis (21) and half the size of the amphiphilic form in detergent-solution. In spite of the smaller yields of cross-linked polypeptides in aminopeptidase cross-linked in situ as compared to isolated aminopeptidase treated with $\mathrm{C}_{8}$ in solution, the molecular weight of the largest product was for several reasons considered to reflect the size of the membrane-bound enzyme. First, the band corresponding to 330.000 dalton polypeptides stained more strongly than smaller cross-linked complexes, suggesting it represents an end product of the reaction, i.e. the fully cross-linked oligomeric enzyme molecule. Second, $\mathrm{C}_{8}$-aminopeptidase prepared in solution and of a degree of modification similar to in situ cross-linked aminopeptidase displayed several products of molecular weight above 330.000 (Figure 4), despite the fact that the concentrations of aminopeptidase in the solution and in the vesicle suspension were comparable and the enzyme as a rough estimate in reality was $10-10^{2}$ fold more concentrated when taking only the membraneous phase into account. Third, the overall interprotomer contact area per protomer is most likely smaller in an oligomer of 330.000 than in a corresponding dimer of 660.000 dalton, implying a higher probability for inter-protomer cross-linking of the dimeric form of aminopeptidase found in solution. Finally it should be mentioned that in cross-linking studies on other complex biological membranes the reactions appear rather incomplete because individual polypeptides as a rule exist in the chemically modified membranes both as components in cross-linked products and as free polypeptides (14, 33).

The assignment of subunit compositions to the bands appearing in SDS-polyacrylamide gel electrophoresis relies on the determination of molecular weights. The values determined for $\alpha$, $\beta$ and $\gamma$ are based on the mobilities of marker proteins and may not be very exact, because aminopeptidase is an integral membrane protein containing $23 \%$ of carbohydrate (21). It was assumed, however, that cross-linked products 
and the free subunits would fit on the same calibration curve. In support, the calculated molecular weights of predicted complexes were similar to molecular weights observed for the polypeptides of $\mathrm{C}_{8}$-aminopeptidase (Figure 3 and Table I). Furthermore the composition of certain complexes were confirmed using a cleavable reagent in combination with two-dimensional electrophoresis (SVEnSSON, SנösTRöm and NoRÉN, manuscript in preparation). Restriction of unfolding due to cross-linking $(11,24)$ is thus considered insignificant in the present study. A result perhaps of the high reagent concentration used in the cross-linking step assuring formation of few bifunctional as compared to monofunctional substitutions.

The subunit composition of subcomplexes of membrane-bound aminopeptidase were based on the 330.000 dalton protein to exist in the quarternary structures $\alpha_{2}, \alpha \beta \gamma$ and $\beta_{2} \gamma_{2}$, where $\alpha$ can be cleaved into $\beta$ plus $\gamma$, but $\gamma$ cannot arise from $\beta$. Experimental evidence for the existence of the $\beta_{2} \gamma_{2}$ oligomer is given by the relatively high yields of $\gamma_{2}$ in aminopeptidase cross-linked in situ. Also the recent finding that both $\alpha$ - and $\beta$-subunits may be inserted in the membrane bilayer (23) supports $\beta_{2} \gamma_{2}$ to be a proper integral membrane protein. For unknown reasons, the routine isolation procedure occassionally resulted in an amphiphilic aminopeptidase essentially free of the $\alpha$-subunit (B. Svensson, unpublished observations). The molecular size of this form of aminopeptidase has not been determined, but it is tempting to suggest that a homogenous population of $\beta_{2} \gamma_{2}$ can exist in vivo. The discrete $a \gamma$ band unambigously points to the presence of membrane-bound $\alpha \beta \gamma$ aminopeptidase oligomers. Finally, the only experimental evidence provided for the existence of the $\alpha_{2}$ oligomer comes from cross-linking of brush border membrane vesicles from the intestine of a pig with ligated pancreatic duct. The half life of this form may be short in normal pigs.

Extending the limitations observed for the subunit composition in the membrane-bound aminopeptidase to the isolated detergent-form of the enzyme and assuming it to be a dimer of the former, its possible subunit structures would be $\alpha_{4}, \alpha_{3} \beta \gamma, \alpha_{2} \beta_{2} \gamma_{2}, \alpha_{3} \gamma_{3}$ and $\beta_{4} \gamma_{4}$. Thus the following general characteristics exist for corresponding polypeptide complexes: the maximum number of any single type of subunit in a complex is four, the sum of the $\alpha$-plus $\beta$ subunits and the sum of the $\alpha$-plus $\gamma$-subunits cannot exceed four. Using these rules the bands in the polypeptide pattern of aminopeptidase cross-linked in solution could be assigned to varying numbers of complexes of $\alpha, \beta$ and/or $\gamma$ in agreement with the predicted complexes (Table II). Considering for example $\mathrm{C}_{7}$-amino-

Table II

Analysis of the band pattern of aminopeptidase cross-linked in solution by $\mathrm{C}_{8}$.

\begin{tabular}{rclc}
\hline Band & Apparent mol.wt. & \multicolumn{1}{c}{ Proposed subunit composition } & Range of calculated mol.wt. \\
\hline 1 & $620.000-670.000$ & $\alpha_{4}, \alpha_{3} \beta, \alpha_{3} \beta \gamma, \alpha_{2} \beta_{2} \gamma, \alpha_{2} \beta_{2} \gamma_{2}, \alpha \beta_{3} \gamma_{2}, \alpha \beta_{3} \gamma_{3}, \beta_{4} \gamma_{3}, \beta_{4} \gamma_{4}$ & $622.000-688.000$ \\
2 & 570.000 & $\alpha_{3} \gamma, \alpha_{2} \beta_{2}, \alpha_{2} \beta \gamma_{2}, \alpha \beta_{2} \gamma_{3}, \beta_{4} \gamma_{2}, \beta_{3} \gamma_{4}$ & $558.000-580.000$ \\
3 & 525.000 & $\alpha \beta_{3}, \beta_{4} \gamma, \beta_{3} \gamma_{3}$ & $516.000-526.000$ \\
4 & 495.000 & $\alpha_{3}, \alpha_{2} \beta \gamma, \alpha \beta_{2} \gamma_{2}$ & $504.000-512.000$ \\
5 & 460.000 & $\alpha_{2} \beta, \alpha_{2} \gamma_{2}, \alpha \beta_{2} \gamma, \alpha \beta \gamma_{3}, \beta_{4}, \beta_{3} \gamma_{2}, \beta_{2} \gamma_{4}$ & $444.000-472.000$ \\
6 & 410.000 & $\alpha \beta_{2}, \beta_{3} \gamma$ & $404.000-408.000$ \\
7 & 390.000 & $\alpha_{2} \gamma, \alpha \beta \gamma_{2}, \beta_{2} \gamma_{3}$ & $384.000-394.000$ \\
8 & 355.000 & $\beta_{3}$ & 354.000 \\
9 & 335.000 & $\alpha_{2}, \alpha \beta \gamma, \alpha \gamma_{3}, \beta_{2} \gamma_{2}, \beta \gamma_{4}$ & $330.000-344.000$ \\
10 & 275.000 & $\alpha \beta, \alpha \gamma_{2}, \beta_{2} \gamma, \beta \gamma_{3}$ & $276.000-290.000$ \\
11 & 230.000 & $\beta_{2}, \beta \gamma_{2}$ & $226.000-236.000$ \\
12 & 215.000 & $\alpha \gamma, \gamma_{4}$ & $216.000-222.000$ \\
13 & 168.000 & $\alpha, \beta \gamma, \gamma_{3}$ & $162.000-172.000$ \\
14 & 118.000 & $\beta$ & 118.000 \\
15 & 108.000 & $\gamma_{2}$ & 108.000 \\
16 & 54.000 & $\gamma$ & 54.000 \\
\hline
\end{tabular}


peptidase the products of 660.000 (band 1) and 330.000 dalton (band 9) stained relatively strongly. In analogy with previous studies on oligomeric proteins $(5,11)$ the present molecular species is suggested to consist of two polypeptide groups of equal size. From the electrophoresis of the unmodified aminopeptidase, the amount of $\alpha$ appeared considerably lower than amounts of $\beta$ and $\gamma$. Accordingly band 3 which was assigned complexes rich in $\beta$ showed higher staining intensity than for example band 4 assigned complexes containing more $\alpha$-polypeptide chains. Moreover, bands 6 and 8 representing only two and one complexes, respectively, were very weak. It is obvious that the experimentally obtained polypeptide pattern fits the working model employed for the subunit structure of the enzyme.

Using the series of diimidates as a molecular ruler reactive amino groups in two neighbouring $y$-subunits were more than $6 \AA\left(C_{5}\right.$, ref. 9) apart, but within the distance of 9-1 I $\AA(9,24)$ of each other as seen by the formation of $\gamma_{2}$ in high yields by $\mathrm{C}_{6}-\mathrm{C}_{8}$. The longer reagents, $\mathrm{C}_{10}$ and $\mathrm{C}_{12}$ (14.5 $\AA$, ref. 9), showed higher capacity for cross-linking $\gamma$ and/or $\gamma_{2}$ with other subunits, whereas 9-11 $\AA$ appeared an ideal length for cross-linking of the $\beta$-subunits. The incompletely resolved bands in the molecular weights ranges $210.000-240.000, \quad 310.000-350.000$ and

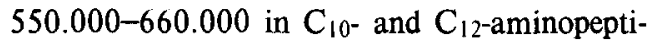
dase may also reflect that these reagents are capable of formation of several or all of the complexes suggested in Table 2, whereas the shorter reagents perhaps only fully cross-link a few of the listed complexes.

The random collisions of membrane proteins may be a problem in interpretation of results from covalent cross-linking. However, millisecond photochemical cross-linking of erythrocyte ghosts resulted in a number of products surprisingly similar to those formed by regular reagents over longer periods of time (14). Also conventional cross-linking of erythrocyte ghosts at low temperature did not change the final polypeptide pattern (33). Similarly cross-linking of membrane-bound aminopeptidase at $4{ }^{\circ} \mathrm{C}$ and room temperature, respectively, resulted in identical polypeptide patterns. Judged by this criterion the observed oligomers appeared to be naturally occurring, as expected also from the molecular properties of the previously characterized hydrophilic form of the enzyme (21) and from the assumed action of pancreatic protease(s) on the $\alpha$-polypeptide chains of the membrane-bound enzyme $(28,32)$.

The $\alpha$-subunits (mol.wt. 168.000) of brush border membrane-bound aminopeptidase were suggested to undergo limited proteolysis in situ with formation of the $\beta$ - and $\gamma$-subunits $(28,32)$. It shall here be further hypothesized that the $\alpha$ subunits in turn are generated by limited proteolysis of a brush border membrane-bound component, $2 \alpha$, of molecular weight 330.000 . The points in direct support of such a hypothesis are: 1) the presence of highly homologous segments in the primary structures of $2 \alpha$ and of $\alpha, \beta$ and $\gamma$, respectively, 2) the apparent affinity of $2 \alpha$, solubilized from the membrane, for antiaminopeptidase $M, 3$ ) and the molecular size of $\alpha$ and $2 \alpha$. Schematically the hypothetical pathway can be described as:

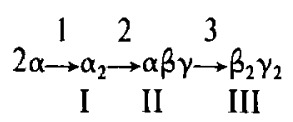

Trypsin can catalyze steps 2 and 3 (28). If the hypothetical step 1 is really significant in vivo, it need not a pancreatic protease because $\alpha$ is the major component of the enzyme preparation from a pig with ligated pancreatic duct (28). It should be emphasized also that it cannot be excluded that the individual subunits may exist in slightly different forms, e.g. $\alpha$ in oligomer $I$ is not necessarily completely identical to $\alpha$ in oligomer II, and slight heterogeneity within an oligomer may also exist. Also the actual sequence of the steps may differ from the suggested pathway or several pathways may operate in parallel, e.g. $\beta$ or $\gamma$ may be split from $2 \alpha$ as the first event. In fact traces of polypeptides of molecular weights 225.000 and 275.000 are occasionally found in preparations of aminopeptidase.

The existence of a large precursor was previously suggested for the dimer sucraseisomaltase, an integral protein-complex of the intestinal brush border membrane (27). However, a single polypeptide chain precursor comprising a segment equal to the sucrase plus a segment equal to the isomaltase moieties was never demonstrated (27). Recently a socalled 
polyprotein precursor was described to all four of the cytoplasmically translated subunits of cytochrome c oxidase (25). The proteolytic processing of the precursor was demonstrated to take place after its association with the inner mitochondrial membrane (26). The hypothesis presented for the route of post-translational modifications of microvillar aminopeptidase follows a similar scheme. As outlined above, however, the events were only deduced from the polypeptide composition of various isolated forms of microvillar aminopeptidase and the structural relationship between these polypeptides. It still has to be investigated whether the reactions really occur in the membrane-bound state, also the location and nature of the protease(s) responsible for the conversions (steps $1-3)$ in vivo have to be clarified. The crosslinking studies provide evidence that the membrane-bound intestinal microvillar aminopeptidase normally exists as a population of molecules differing in subunit composition. Pancreatic protease(s) is/are most likely playing a role in the generation of some of these forms (28). Comparative studies on the chemical properties of the subunits of ordinary preparations of hydrophilic or amphiphilic microvillar aminopeptidase as well as preparations of the enzyme obtained in the presence of various protease inhibitors are in progress in these laboratories with the purpose of getting more insight into the pathway of proteolytic processing leading to the form(s) of the enzyme acting in the intestine.

\section{ACKNOWLEDGEMENTS}

Sincere thanks are due to Mr. J. Svaneborg for expert technical assistance and stimulating discussions and to Mr. H. EMMÉ for making the slab-gel electrophoresis apparatus. Drs. O. NoRÉN and H. SJÖSTRÖM prepared the anti-aminopeptidase M-Sepharose and purified the subunits, respectively. Dr. L. Christiansen, Department of Surgical Gastroenterology C, Rigshospitalet, Denmark, is thanked for performing ligation of the pig pancreatic duct. I am indebted to Professor M. OTTESEN for very helpful criticism of the manuscript. Mrs. B. Corneliussen is gratefully acknowledged for the amino acid analyses.

\section{REFERENCES}

1. Baskin, R. J. \& S. Hanna: Cross-linking of the $\left(\mathrm{Ca}^{2+}+\mathrm{Mg}^{2+}\right)$-ATPase protein. Biochim. Biophys. Acta 576, 61-70 (1979)

2. Bhakdi, S., B. Bhakdi-Lehnen \& O. J. BJerRUM: Detection of amphiphilic proteins and peptides in complex mixtures. Charge-shift crossed immunoelectrophoresis and two-dimensional charge-shift electrophoresis. Biochim. Biophys. Acta 470, 35-44 (1977)

3. BonNer, W. M. \& R. A. LASKey: A film detection method for tritium-labelled proteins and nucleic acids in polyacrylamide gels. Eur. J. Biochem. 46, 83-88 (1974)

4. Bordier, C. \& A Crettol-Jäninen: Peptide mapping of heterogeneous protein samples. $\mathrm{J}$. Biol. Chem. 254, 2565-2567 (1979)

5. Carpenter, F. H. \& K. T. Harrington: Intermolecular cross-linking of monomeric proteins and cross-linking of oligomeric proteins as a probe of quaternary structure. Application to leucine aminopeptidase (bovine lens). J. Biol. Chem. 247, 5580-5586 (1972)

6. Cueveland, D. W., S. G. Fischer, M. W Kirschner \& U. K. LaemmLl: Peptide mapping by limited proteolysis in sodium dodecyl sulfate and analysis by gel electrophoresis. J. Biol. Chem. 252, 1102-1106 (1977)

7. Davies, G. E. \& G. R. Stark: Use of dimethyl suberimidate, a cross-linking reagent, in study. ing the subunit structure of oligomeric proteins. Proc. Nat. Acad. Sci. USA, 66, 651-656 (1970)

8. Frasch, C. E.: Removal of detergent by ultrafiltration. Dialog (Amicon), Febr. 1-3 (1976)

9. Hajdu, J., S. R. WYss \& H. AEBi: Properties of human erythrocyte catalases after cross-linking with bifunctional reagents. Eur. J. Biochem. 80, 199-207 (1977)

10. Hamilton, S. L., M. Mclaughi.in \& A. Karlin: Formation of disulfide-linked oligomers of acetylcholine receptor in membrane from Torpedo electric tissue. Biochemistry 18, 155-163 (1979)

11. Hucho, F., H. Müll.ner \& H. Sund: Investigation of the symmetry of oligomeric enzymes with bifunctional reagents. Eur. J. Biochem. 59, 79-87 (1975)

12. JI, T. H.: The application of chemical crosslinking for studies on cell membranes and the identification of surface receptors. Biochim. Biophys. Acta 559; 39-69 (1979)

13. Kessler, M., P. Acuto, C. Storelli, H. Murer, M. MÜller \& G. Semenza: A modified procedure for the rapid preparation of efficiently 
transporting vesicles from small intestinal brush border membranes. Their use in investigating some properties of D-glucose and choline transport systems. Biochim. Biophys. Acta 506, 136154 (1978)

14. KıEHм, D. J. \& T. H. JI: Photochemical crosslinking of cell membranes. A test for natural and random collisional cross-links by millisecond cross-linking. J. Biol. Chem. 252, 8524-8531 (1977)

15. Laemmli, U. K.: Cleavage of structural proteins during the assembly of the head of bacteriophage T4. Nature 227, 680-685 (1970)

16. Lewis, W. G., J. M. Basford \& P. L. Walton: Specificity and inhibition studies of Armillaria mellea protease. Biochim. Biophys. Acta 522 , $551-560$ (1978)

17. Louvard, D., S. Maroux, J. Baratti, P. Desnuelle \& S. Mutaftschiev: On the preparation and some properties of closed membrane vesicles from hog duodenal and jejunal brush border. Biochim. Biophys. Acta 291, 747-763 (1973)

18. Maestracci, D., J. Schmitz, H. Preiser \& R. K. CRANE: Proteins and glycoproteins of the human intestinal brush border membrane. Biochim. Biophys. Acta 323, 113-124 (1973)

19. Maizel Jr., J. V.: Polyacrylamide gel electrophoresis of viral proteins. Meth. Virology 5, 179246 (1971)

20. Maroux, S. \& S. Louvard: On the hydrophobic part of aminopeptidase and maltases which bind the enzyme to the intestinal brush border membrane. Biochim. Biophys. Acta 419, 189195 (1976)

21. Maroux, S., D. Louvard \& J. Baratti: The aminopeptidase from hog intestinal brush border. Biochim. Biophys. Acta 321, 282-295 (1973)

22. Nathanson, N. M. \& Z. W. Hall: Subunit structure and peptide mapping of junctional and extrajunctional acetylcholine receptors from rat muscle. Biochemistry 18, 3392-3401 (1979)

23. NorÉn, O. \& H. SJöström: The insertion of pig microvillus aminopeptidase into the membrane as probed by ${ }^{125}$ I-iodonaphthylazide. Eur. J. Biochem., in the press.

24. Peters, K. \& F. M. Richards: Chemical crosslinking: reagents and problems in studies of membrane structure. Ann. Rev. Biochem. 46, 523-51 (1977)

25. Poyton, R. O. \& E. McKemmie: A polyprotein precursor to all four cytoplasmically translated subunits of cytochrome coxidase from Saccharomyces cerevisiae. J. Biol. Chem 254, 6763-6771 (1979)

26. Poyton, R. O. \& E. McKemmie: Post-translational processing and transport of the polyprotein precursor to subunits IV to VII of yeast cytochrome $c$ oxidase. J. Biol. Chem. 254, 6772-6780 (1979)

27. Semenza, G.: The mode of anchoring of sucraseisomaltase to the small intestinal brush-border membrane and its biosynthetic implications. In: Processing and turnover of proteins and organelles in the cell, Symp. 12th FEBS Meet., Dresden, July 2-8, 1978 (S. Rapoport \& T. Schewe, Eds.). Pergamon Press, London 1979

28. Suöström, H. , O. Norén,L. Jeppesen, M. Staun, B. Svensson \& L. Christiansen: Purification of different amphiphilic forms of a microvillus aminopeptidase from pig small intestine using immunoadsorbent chromatography. Eur. J. Biochem. 88, 503-511 (1978)

29. Stark, G. R., W. H. Stein \& S. Moore: Reactions of the cyanate present in aqueous urea with amino acids and proteins. J. Biol. Chem. $235,3177-3181(1960)$

30. Svendsen, I.: Studies on the carbamylation of subtilisin type Novo. Compt. Rend. Trav. Lav. Carlsberg 36, 235-246 (1967)

31. Thomas, J. O. \& R. D. Kornberg: An octamer of histones in chromatin and free in solution Proc. Nat. Acad. Sci. USA, 72, 2626-2630 (1975)

32. Wacker, H., P. Lehky, F. Vanderhaeghe \& E. A. Stein: On the subunit structure of particulate aminopeptidase from pig kidney. Biochim. Biophys. Acta 429, 546-554 (1976)

33. Wang, K. \& F. M. Richards: An approach to nearest neighbor analysis of membrane proteins. Application to the human erythrocyte membrane of a method employing cleavable cross-linkages. J. Biol. Chem. 249, 8005-8018 (1974)

34. Ziemiecki A. \& H. GarofF: Subunit composition of the membrane glycoprotein complex of Semliki Forest virus. J. Mol. Biol. 122, 259-269 (1978)

Note added in proof: Sucrase-isomaltase was recently demonstrated to be synthesized as a one-chain polypeptide precursor that is split into subunits after its transfer to the microvillus membrane. (H.-P. HaURI, A. Quaronı, and K. J. Isselbacher, Proc. Natl. Acad. Sci. 76, 5183-5186 (1979)). 